\title{
An ethical analysis of the policies of British community and hospital care for mentally ill people: a commentary
}

\author{
P G Campbell Friern and University College Hospitals, London
}

If 'community care' really is a new kind of treatment for people with mental illness (and many claims are made for the attitudes of innovation and visionary creativity required to press for its implementation) then it is very necessary that the medical profession and the general public examine it with at least the degree of ethical concern that would be afforded other experimental treatments. On this basis, for example, it is highly questionable whether some current plans to transfer long-term hospital patients to new types of environment entail an acceptable balance of risk versus benefit. It is striking, however, that such ethical questions are not, and perhaps cannot be, dealt with by the agents of change, who in my experience mainly come from outside the psychiatric medical and nursing professions, are largely ignorant about severe mental illness and are motivated by, on the one hand, middleclass liberal ideals or, on the other, line-management directives to get on with the job of closing mental hospitals as fast as possible. Even if instantly misheard as arguing for vested interests, doctors have the unusual privilege of still being free to express an informed view derived from personal responsibility for and experience of the care of mentally ill people.

When I asked a very senior administrator with responsibilities to implement the half-baked policy of closing one of the hospitals in which I work about the ethics of removing patients from hospital to a much more deprived environment, he could only suggest the question should be referred to the hospital's ethical committee. Since the progress of policy development about this particular closure has so far shown an extraordinary imperviousness to factual information about the scale of need and to medical advice about the services required, it will be interesting to see the impact of such advice, if it can be obtained.

It is brave of Pattison and Armitage to try to raise the level of debate about 'community care' by questioning the ethical basis of its policies at a time when such unease is readily condemned as reactionary or 'institutionalised'. It is important that we do not all

\section{Key words}

Care of the mentally ill; hospital $\mathbf{v}$ community care for the mentally ill. have to enthuse about the magnificence of the emperor's new clothes. The difficulty, as their discussion shows, is to find within the broad mish- $N$ mash of self-evidently desirable propositions upon $\omega$ which arguments in favour of 'community care' are $\nexists$ largely based, specifiable hypotheses for analysis. 은 They would do well to question more explicitly than they do the prevailing assumption that closure of $\infty$ mental hospitals is an obligatory expression of policies $\mathbb{D}$ in favour of community services outside hospital. In $\mathbb{\mathbb { D }}$ my own locality there is good evidence that this dichotomy between hospital and community is false $\stackrel{\Phi}{-}$ and is not even justified by financial arguments. By $\vec{\varphi}$ focusing priority expenditure on the relocation of th long-stay mental hospital clientele, and at the same time depriving the services of the flexible, long-sto support of a mental hospital site, which in this instance can offer near-irreplaceable facilities of space, economies of scale, a sense of community for destitute people, and specialised amenities for treatment, education and research, current planning has actually interrupted the progress of local community developments, damaged existing services and may make the fulfilment of hopes for better services outside hospital less, rather than more, probable for some important, yet already underprivileged, groups of people.

At the most immediately practical level, when an attempt is made to assess the impact of 'community care' policies in recent years on, for example, the 0 treatment opportunities for terribly disadvantaged people with long-term mental illness drifting to inner- $\frac{}{0}$ city areas, meaningful ethical questions may be readily posed, but the factual evidence on such issues is often or ruled out of court by the protagonists of change as not $N$ bearing on the overall desirability of the strategy of $N$ 'community care'. As shown by the recent report of the $\omega$ Social Services Select Committee (1), no amount of evidence about the impracticability of fulfilling the aims of the strategy within the financial and time limits $\stackrel{\Phi}{?}$ currently proposed alters the adherence to the strategy $?$ as a whole. If the new treatment were a drug, it is as if the experimenter had no way of abandoning the drug $\overrightarrow{\mathbb{D}}$ trial as too hazardous or too inadequately designed and $\frac{?}{\oplus}$ endlessly justified its continuation by pointing to the $\varrho$ benevolence of its intentions and the good results ${ }^{\sigma}$ 
evident in some cases. The 'community care' approach has already demonstrated severely adverse effects as well as beneficial ones (2), but who is ready to undertake the responsibility of correcting them?

The authors' valuable endeavour in highlighting several important questions about the principles of community care would be strengthened by reference to some more recent literature, including the crucial role of the Maudsley, Exeter, Hackney and Worcester experiments in initiating alternatives to mental hospital care for example (3) in bolstering arguments for trying to multiply and extend these special and qualifiable successes on a massive scale. There is also a need for a more detailed examination of the assumptions implicit in community care policies in the United Kingdom, as was usefully undertaken by Hawks in 1975 (4) who concluded, very much in line with Pattison and Armitage, that 'the movement towards community care has many of the attributes of a moral enterprise which, unless substantiated by benefits to the patient or his family, may be the latest diversion of the psychiatric conscience from the care and treatment of the chronic mentally ill'. The authors' attempt at an ethical analysis needs to be extended to show how specific issues about the implementation of policies in a particular place may, in the light of factual evidence, be broken down into identifiable and answerable questions. Without this there is a great danger (as I have repeatedly experienced) that the importance of ethical debate is dismissed as hopelessly vague, imponderable and negatively obstructive by those impatient to get on with the job of closing hospitals (and to meet directives with important implications for career advancement). Broken down into more particular questions about the estimation of benefits and risks for particular mentally ill people in particular localities, the ethical (as opposed to the financial, geographical, architectural and other issues which crowd in on any discussion of 'community care') can be seen a bit more clearly as difficult but essential and examinable issues, for which ordinary general, rather than specifically medical, standards of humanitarian concern and objective truth provide guidance.

When I see the squalor and degradation in which many mentally ill patients disowned by hospitals and local authorities currently live, when I hear that our precious nurses (now condemned in the newspeak of 'community care' as 'custodial' and 'institutionalised') are leaving a hospital identified as due to close, or when I read some of the vacuously simplistic proposals about the new services envisaged, I fear it may already be too late. The property speculators must be rubbing their hands.

Dr P G Campbell MA BM MRCP FRCPsych MPhil is Consultant Psychiatrist, Friern and University College Hospitals, Friern Barnet Road, London N11 3BP.

\section{References}

(1) Second Report from the Social Services Committee Session 1984-5. Community care: with special reference to adult mentally ill and mentally handicapped people. Volumes I, II and III. London: Her Majesty's Stationery Office, 1985.

(2) Report of the Richmond Fellowship Enquiry. Mental health and the community. London: Richmond Fellowship Press, 1983.

(3) Wing J K, ed. Long-term community care: experience in a London borough. Psychological medicine. Monograph supplement no 2. Cambridge: Cambridge University Press, 1982.

(4) Hawks D. Community care: an analysis of assumptions. British journal of psychiatry 1975; 127: 276-285.

\section{Editor's note}

The editor has been unable to obtain a commentary arguing the case tending to favour closure of mental hospitals and reliance instead on 'community care'. Perhaps publication of the preceding articles will evoke such responses.

(continued from page 140)

(31) Plant R. Community and ideology. London: Routledge and Kegan Paul, 1974: 8.

(32) See reference (20): ch 2.

(33) See reference (18): 20.

(34) Scull A T. Museums of madness. London: Allen Lane, 1979: ch 3.

(35) Leighton A H. Caring for mentally ill people. Cambridge:
Cambridge University Press, 1982: 10.

(36) Szasz T S. Law, liberty and psychiatry. London: Routledge and Kegan Paul, 1974.

(37) Raphael D D. Problems of political philosophy. London: Macmillan; 1976: 115.

(38) Miller D. Social justice. Oxford: Oxford University Press, 1976: ch 1. 